\title{
Cancer biology: mechanism of antitumour action of vorinostat (suberoylanilide hydroxamic acid), a novel histone deacetylase inhibitor
}

\author{
VM Richon*,I \\ 'Merck Research Laboratories, Department of Cancer Biology and Therapeutics, BMB9-101, 33 Avenue Louis Pasteur, Boston, MA 02115, USA
}

Histone deacetylase (HDAC) inhibitors represent a potential new class of antitumor agents. Vorinostat (suberoylanilide hydroxamic acid or SAHA) is a potent inhibitor of HDAC activity and has undergone initial evaluation in several Phase I and II clinical trials. HDACs are enzymes that catalyse the removal of the acetyl moiety from the lysine residues of proteins, including the core nucleosomal histones. Together with histone acetyltransferases (HATs), HDACs regulate the level of protein acetylation. Alterations in both HAT and HDAC activity have been reported to occur in cancer. HAT activity has been found to be disrupted by translocation, amplification, overexpression or mutation in a variety of cancers, including those of haematological or epithelial origin. HDACs have been found to be overexpressed or associated with oncogenic transcription factors. Vorinostat induces growth arrest, differentiation or apoptosis in a variety of transformed cells. The antiproliferative effects of vorinostat are believed to be due to druginduced accumulation of acetylated proteins, including the core nucleosomal histones and other proteins (e.g., BCL6, p53 and Hsp90). Phase I and II trials have been conducted for the oral formulations of vorinostat, and results show that vorinostat inhibits its target enzyme (HDAC) in peripheral mononuclear cells and tumour tissue at doses that are well tolerated. Antitumour activity has been seen in patients with both haematological and solid tumours.

British Journal of Cancer (2006) 95, S2-S6. doi: I0.1038/sj.bjc.6603463 www.bjcancer.com

(c) 2006 Cancer Research UK

Keywords: histone deacetylase; vorinostat; chromatin

Although a key characteristic of neoplastic transformation is unregulated cellular proliferation, cancer cells nevertheless retain their ability to undergo differentiation or apoptosis under certain circumstances (Marks et al, 2001). Research efforts have been focused on attempting to exploit this characteristic of tumour cells by identifying new anticancer therapies capable of triggering growth arrest, differentiation and/or apoptosis of transformed cells. In this regard, a new class of antitumour agents - histone deacetylase (HDAC) inhibitors - has received particular attention.

The HDAC inhibitor vorinostat (suberoylanilide hydroxamic acid or SAHA) blocks cancer cell proliferation both in vitro and in vivo with little or no toxicity to normal cells and has undergone evaluation in several Phase I and II clinical trials (Kelly et al, 2003, 2005; Duvic et al, 2005). This review discusses the effects of HDAC in modulating gene expression via histone acetylation and the role of abnormal HDAC activity in cancer development, summarises the wealth of in vitro and in vivo data demonstrating the antitumour effects of vorinostat, and explores current hypotheses on the potential mechanism(s) of action of vorinostat that may contribute to its antitumour activity.

\section{ROLE OF HDAC IN REGULATING GENE EXPRESSION AND CANCER DEVELOPMENT}

Nucleosomes comprise the repeating unit of chromatin and serve to organise and compress the DNA in the nucleus. They are

*Correspondence: Dr VM Richon; E-mail: victoria_richon@merck.com composed of the octamer of core histones (two molecules each of histones $\mathrm{H} 2 \mathrm{~A}, \mathrm{H} 2 \mathrm{~B}, \mathrm{H} 3$ and $\mathrm{H} 4$ ) spanning approximately $200 \mathrm{bp}$ of DNA. The acetylation status of histones plays an important role in regulating gene expression by altering the structure of chromatin (Grunstein, 1997; Gregory et al, 2001). Regulation of histone acetylation is controlled by two enzyme families: histone acetyltransferases (HAT), which catalyses the addition of acetyl moieties to lysine residues of proteins, and histone deacetylases (HDAC), which catalyses their removal. HAT promotes gene transcription by acetylating histones, thereby facilitating an open chromatin structure. In contrast, HDACs deacetylate histones thereby facilitating a closed chromatin structure and hence transcriptional repression. Specifically, HDACs are believed to remove an acetyl group from the $\varepsilon$-amino group of the lysine side chain of histones $\mathrm{H} 2 \mathrm{~A}, \mathrm{H} 2 \mathrm{~B}, \mathrm{H} 3$ and $\mathrm{H} 4$, thereby reconstituting the positive charge on the lysine residues.

Three classes of HDAC have so far been identified: Classes I, II and III (for detailed review see Marks and Dokmanovic, 2005 and Verdin et al, 2003). The catalytic domain of Class I and II HDACs is NAD-independent and zinc-dependent, whereas the domain of Class III is NAD-dependent and zinc-independent. To date, a total of 11 Classes I and II human HDACs have been described, which are categorised according to the homology of their catalytic domain and structure (Figure 1). Class IIA enzymes have a long amino terminus and IIB enzymes have two catalytic domains. The different HDACs form large multiprotein complexes, including for example MTA2, Mi-2 and SMRT/N-CoR.

Alterations in the enzymes modifying histone acetylation are important from a cancer biology perspective in that HDAC is 
overexpressed in certain human cancers and is recruited by oncogenic transcription factors. For example, HDAC appears to be overexpressed in gastric (Song et al, 2005), prostate (Halkidou et al, 2004), and colon cancer (Zhu et al, 2004) and aberrant HDAC activity may also occur in certain forms of leukaemia (Fenrick and Hiebert, 1998) and lymphoma (Table 1) ([Lemercier et al, 2002). In acute promyelocytic leukaemia, for example, the transcriptional activator retinoic acid receptor alpha $(\operatorname{RAR} \alpha)$ is fused with the promyelocytic leukaemia (PML) gene on chromosome 15 forming a complex (PML-RAR $\alpha$ ) that results in HDAC recruitment and transcriptional repression (Grignani et al, 1998; He et al, 1998). Genes that encode HAT can also be translocated, amplified, overexpressed and/or mutated in various cancers, including haematological and epithelial malignancies (Table 1). One model of cancer formation, therefore, is the generation of deacetylated proteins due to the overactivity of HDAC or the inactivation of HAT.

\section{VORINOSTAT - A POTENT INHIBITOR OF HDAC ACTIVITY}

Vorinostat (suberoylanilide hydroxamic acid or SAHA) is a nanomolar inhibitor of HDAC activity that has undergone initial evaluation in multiple Phase I and II clinical trials. Vorinostat is a small molecular weight $(<300)$ linear hydroxamic acid compound that inhibits HDAC activity thereby inducing the accumulation of acetylated histones as well as nonhistone proteins, blocks the proliferation of cultured cells, and inhibits tumour growth in a variety of animal models. Vorinostat is a broad inhibitor of HDAC activity and inhibits both classes I and II enzymes (Marks et al,

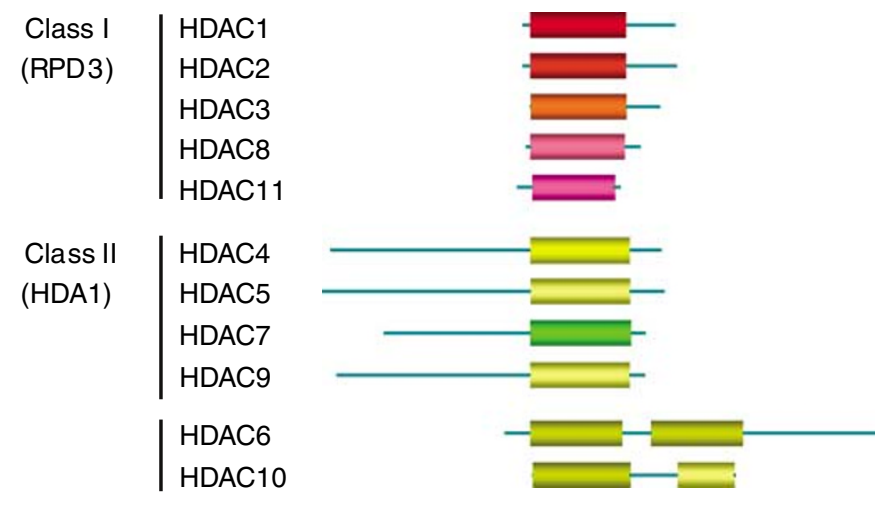

Figure I Classes I and II human HDACs categorised according to the homology of their catalytic domain and structure.

Table I Summary of acetylation defects observed in various cancers

\begin{tabular}{lll}
\hline Leukemia & HAT fusions & HDAC mediated \\
& MOZ/CBP & PMLRARalpha \\
MOZ/p300 & PLZF/RARalpha \\
MOZ/TIF-2 & AMLI fusion \\
MLL/CBP & \\
MLL/p300 & BCL6 \\
Lymphoma & & STAT5 \\
Epithelial cancers & p300 mutations in colorectal, gastric, breast, \\
pancreatic carcinomas/cancer cell lines
\end{tabular}

2001;Marks and Dokmanovic, 2005). As with other HDAC inhibitors in clinical development, vorinostat does not inhibit HDACs belonging to Class III.

Crystallographic studies have revealed that vorinostat inhibits HDAC activity by binding in the active site of the enzyme (Finnin et al, 1999). As shown in the molecular netting diagram (Figure 2), the hydroxamic end of the molecule binding to the zinc atom in the HDAC catalytic site, with the phenyl ring of vorinostat projecting out of the catalytic pocket on to the surface of HDAC.

\section{IN VITRO ANTITUMOR ACTIVITY OF VORINOSTAT}

Vorinostat has been shown to inhibit the proliferation of a wide variety of transformed cells in vitro, including lymphoma, myeloma, leukaemia, and non-small cell lung carcinoma with concentrations that inhibit growth by $50 \%$ compared to no treatment ranging from approximately 0.5 to $10 \mu \mathrm{M}$ (Table 2) (Kelly et al, 2005). The inhibitory effects of vorinostat on cell proliferation tended to vary across multiple cell lines of a particular tumour type. This variability is illustrated by the recent findings from Koeffler and co-workers showing that vorinostat produced a profound but variable degree of inhibition of proliferation of lymphoma and leukaemia cells, including Burkitt, B-cell acute lymphoblastic leukaemia (B-ALL), MCL, DLBCL, ATL

Vorinostat (suberoylanilide hydroxamic acid, SAHA)<smiles>O=C(CCCCCCC(=O)Nc1ccccc1)NO</smiles>

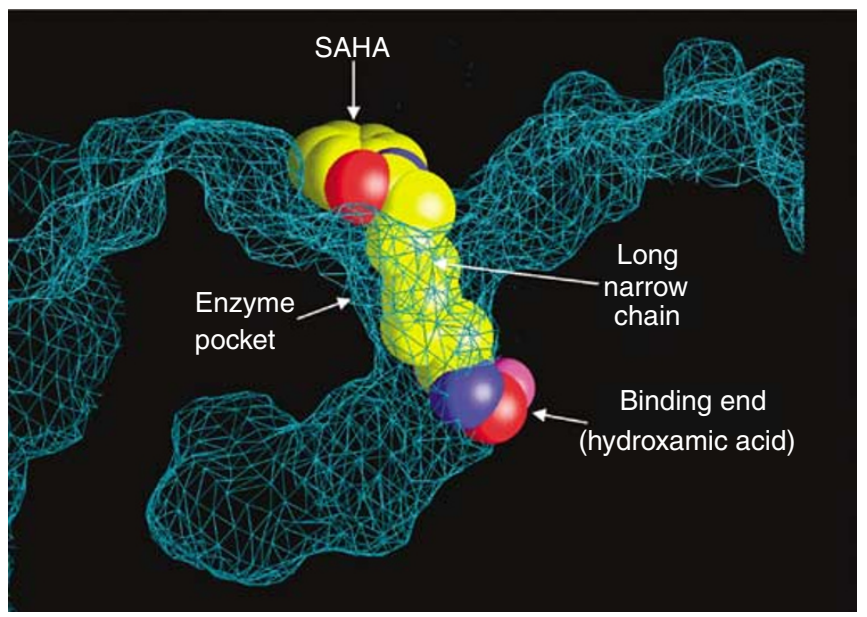

Figure 2 Vorinostat inhibits HDAC activity by binding to the pocket of the catalytic site. The hydroxamic acid moiety of vorinostat binds to a zinc atom (pink), allowing the rest of the molecule to lie along the surface of the HDLP protein (Marks et al, 200I).

Table 2 Vorinostat inhibits proliferation of a variety of transformed cells in vitro

\begin{tabular}{ll}
\hline Lymphoma & Breast adenocarcinoma \\
Myeloma & Pancreatic cancer \\
Leukaemia & Glioblastoma \\
Mesothelioma & Prostate cancer \\
Non-small cell lung carcinoma & Ovarian cancer \\
Bladder carcinoma & Melanoma \\
Colon carcinoma & Renal cell carcinoma \\
Thyroid cancer & Endometrial cancer \\
\hline
\end{tabular}


and T-cell (Sakajiri et al, 2005). For example, in the case of DLBCL, the $\mathrm{ED}_{50}$ for inhibition of cellular proliferation was $0.83 \mu \mathrm{m}$ for the SUDHL6 cell line and $1.9 \mu \mathrm{m}$ for the SUDHL16 cell line.

In addition to inhibiting the proliferation of transformed cells, vorinostat also inhibits proliferation of normal cells, as evidenced by comparing the effects of vorinostat on a matched panel of cells lines - normal human lung fibroblast cells (WI-38) and SV40 large $\mathrm{T}$ antigen transformed WI-38 (VA-13 cells) (Ungerstedt et al, 2005). Vorinostat resulted in a dose-dependent inhibition of proliferation of both cell types but was found to be selectively toxic to transformed cells, inducing death in tumour cells but leaving normal cells growth-inhibited but viable (Marks et al, 2001). The reason for this selective toxicity is incompletely understood, however, these studies provide evidence for an important role of thioredoxin in mediating the resistance of normal cells to vorinostat-induced cell death.

\section{IN VIVO ANTITUMOUR ACTIVITY OF VORINOSTAT}

Vorinostat inhibits tumour growth in rodent models of a variety of solid tumours and haematological malignancies by both parenteral and oral administration (Table 3), including prostate cancer, (Butler et al, 2000) leukaemia (He et al, 2001), breast cancer (Cohen et al, 1999;Cohen et al, 2002), glioma (Eyupoglu et al, 2005) and lung cancer (Desai et al, 2003). Inhibition of tumour growth occurs at vorinostat doses that have little or no toxicity, as evaluated by weight gain, histological studies and gross anatomic examination of tissues/organs at autopsy (Butler et al, 2000). Vorinostat administered in the diet has been shown to inhibit the development of rat mammary tumours induced by the carcinogen $\mathrm{N}$-methylnitrosourea (Cohen et al, 1999). Administration of

Table 3 Parenteral or oral administration of vorinostat inhibits growth of a variety of tumours in rodents

\begin{tabular}{ll}
\hline Parenteral administration & Oral administration \\
\hline Prostate cancer (CWR22 xenograft) & $\begin{array}{l}\text { Breast adenocarcinoma } \\
\text { (N-methylnitrosourea-induced) }\end{array}$ \\
$\begin{array}{l}\text { Leukaemia (acute promyelocytic leukaemia } \\
\text { Lung tumours (tobacco-specific } \\
\text { nitrosamine-induced) }\end{array}$ \\
$\begin{array}{l}\text { Lymphoma (mantle cell, E } \mu \text {-myc transgenic) } \\
\text { Glioma (F98 cells) }\end{array}$ \\
\hline
\end{tabular}

vorinostat decreased tumour incidence and inhibited the growth of established mammary tumours (Cohen et al, 2002).

Vorinostat has also been shown to suppress growth of a transplanted androgen-dependent human prostate tumour (CWR222) in nude mice (Butler et al, 2000). At a dose of $50 \mathrm{mg} \mathrm{kg}^{-1} \mathrm{day}^{-1}$, vorinostat decreased the mean final tumour volume by $97 \%$ compared with controls without detectable toxicity. Within $6 \mathrm{~h}$ of vorinostat administration, an increase in the accumulation of acetylated core histones was detected in CWR22 tumours.

On the basis of these and other studies, vorinostat has undergone evaluation in Phase I and II clinical trials in patients with solid tumours and haematological malignancies, including cutaneous T-cell lymphoma (Kelly et al, 2005, 2003; Duvic et al, 2005). These clinical studies are reviewed in detail in other articles comprising this supplement.

\section{MECHANISM OF ACTION OF VORINOSTAT}

The mechanism for the antiproliferative effect of vorinostat is believed to be the result of inhibition of HDAC activity, resulting in the accumulation of acetylated proteins, including histones. Inhibition of HDAC activity by vorinostat has multiple cellular effects (Johnstone and Licht, 2003; Secrist et al, 2003). These effects include an alteration in the transcription of a finite number of genes $(2-5 \%$ of expressed genes) via acetylation of histones and transcription factors, as well as nontranscriptional effects such as cell cycle arrest via inhibition of mitosis (Figure 3) (Marks et al, 2004). Vorinostat has been shown to impact the expression of several genes, some of which are induced (p21 ${ }^{\text {WAF1 }}$, TBP-2, gelsolin, metallothionein 1L, histone $\mathrm{H} 2 \mathrm{~B}$ ) while others are repressed (cyclin D1, ErbB2, thymidylate synthase, importin b) (Glaser et al, 2003). Induction of gene expression for the cell kinase inhibitor $\mathrm{p} 21^{\mathrm{WAF} 1}$ has been shown for several HDAC inhibitors including vorinostat and this effect may play a critical role in the growth arrest of transformed cells (Richon et al, 2000). Vorinostat induces up to a nine-fold increase in $\mathrm{p} 21^{\mathrm{WAF} 1} \mathrm{mRNA}$ and protein in T24 bladder carcinoma cells (Richon et al, 2000). This effect appears to be due in part to an increase in the rate of gene transcription associated with acetylation of the histones $\mathrm{H} 3$ and $\mathrm{H} 4$ associated with the $\mathrm{p} 21^{\mathrm{WAF} 1}$ promoter (Richon et al, 2000; Gui et al, 2004).

Vorinostat may also promote the acetylation of numerous transcription factors, including androgen receptor, E2F-1, YY1, Smad7, EKLF, p53, BCL-6, HIF-1, NF-Y, NF-kappaB and GATA-1

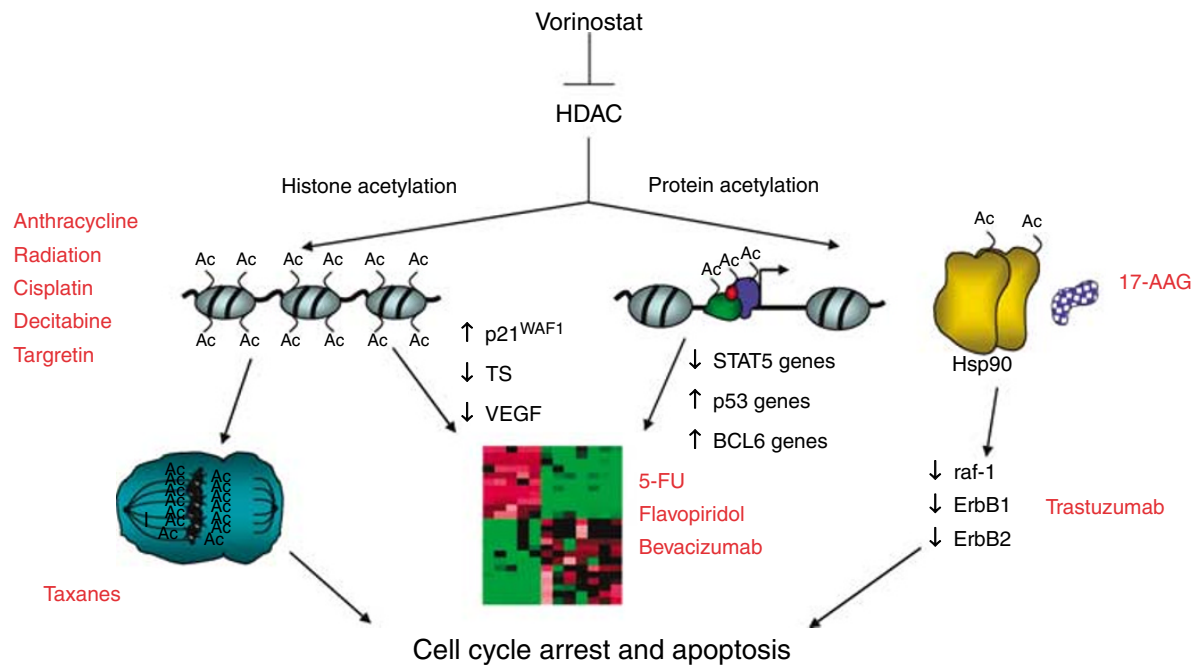

Figure 3 Proposed mechanisms of action of vorinostat in inducing tumor cell cycle arrest and apoptosis. 


\begin{tabular}{|c|c|c|}
\hline Study & Combination & Cell lines \\
\hline Almenara et al (2002) & Vorinostat+flavopiridol & Leukaemia (U937) \\
\hline Kim et al (2003) & Vorinostat+VP-16, ellipticine, doxorubicin, or cisplatin & Human glioblastoma (D54), breast (MCF-7) \\
\hline Nimmanapalli et al (2003) & Vorinostat+imatinib & Chronic myelocytic leukaemia (LAMA-84) \\
\hline Rahmani et al (2003) & Vorinostat+Hsp90 antagonist (17-allylamino- I7-demethoxygeldanamycin) & Human leukaemia (U937). \\
\hline Marchion et al (2004) & Vorinostat+topoisomerase II inhibitors & Breast \\
\hline Rundall et al (2004) & Vorinostat+NF-kappaB inhibitor (BAY-I I-7085) & NSCLC (A549, HI57, H358, H460, HI299) \\
\hline Chinnaiyan et al (2005) & Vorinostat+radiation & Prostate (DUI45) and glioma (U373vIII) \\
\hline Ocker et al (2005) & Vorinostat+5-FU+irinotecan & Hepatoma (HepG2, Hep IB and MH-7777A) \\
\hline Rahmani et al (2005) & Vorinostat+perifosine & Leukaemia (U937, HL-60 and Jurka) \\
\hline
\end{tabular}

(Marks et al, 2001; Secrist et al, 2003). Like histone acetylation, transcription factor acetylation may result in an alteration in the expression of certain genes. For example, acetylation of the p53 transcriptional activator leads to increased binding of p53 to DNA, which in turn, increases the expression of p53-regulated genes. Patients with lymphoma show increased activity of the transcriptional repressor BCL6, and acetylation of BCL6 can give rise to an inhibition of transcriptional repression by BCL6 (Bereshchenko et al, 2002).

In addition to histones and transcription factors, HDAC inhibitors have also been shown to acetylate the lysine residues of a number of proteins, including $\alpha$-tubulin and the heat-shock protein Hsp90. Inhibition of HDAC6 activity leads to acetylation and disruption of Hsp90 and this, in turn, may lead to decreases in activity of progrowth and prosurvival client proteins, such as Bcr-Abl, mutant FLT-3, c-Raf and AKT in human leukaemia cells (Bali et al, 2005).

Evidence also exists that HDAC inhibitors influence the ability of tumour cells to undergo mitosis (Secrist et al, 2003). By causing an increase in acetylated histones and other proteins, HDAC inhibitors may disrupt the cell cycle and induce apoptosis of tumour cells by targeting cell cycle checkpoint controls - a $\mathrm{G}_{2}$ check point, which is often defective in tumour cells, and a mitotic spindle check point (Warrener et al, 2003). In vitro studies indicate that HDAC inhibitors give rise to aberrant spindles most likely by interfering with chromosome attachment, thereby producing mitotic accumulation without affecting mitotic microtubules (Sandor et al, 2000).

Further research into the mechanism(s) of action of vorinostat as well as delineation of its clinical utility in various cancer types should help formulate rational combinations with other chemotherapeutic agents that may provide synergistic or additive antitumour efficacy. Based on a mechanistic rationale, vorinostat has the potential to be combined with several different types of

\section{REFERENCES}

Almenara J, Rosato R, Grant S (2002) Synergistic induction of mitochondrial damage and apoptosis in human leukemia cells by flavopiridol and the histone deacetylase inhibitor suberoylanilide hydroxamic acid (SAHA). Leukemia 16: 1331-1343

Bali P, Pranpat M, Bradner J, Balasis M, Fiskus W, Guo F, Rocha K, Kumaraswamy S, Boyapalle S, Atadja P, Seto E, Bhalla K (2005) Inhibition of histone deacetylase 6 acetylates and disrupts the chaperone function of heat shock protein 90: a novel basis of antileukemia activity of histone deacetylase inhibitors. J Biol Chem 280: $26729-26734$

Bereshchenko OR, Gu W, Dalla-Favera R (2002) Acetylation inactivates the transcriptional repressor BCL6. Nat Genet 32: 606-613

Butler LM, Agus DB, Scher HI, Higgins B, Rose A, Cordon-Cardo C, Thaler HT, Rifkind RA, Marks PA, Richon VM (2000) Suberoylanilide hydroxamic acid, an inhibitor of histone deacetylase, suppresses the growth of prostate cancer cells in vitro and in vivo. Cancer Res 60: $5165-5170$ anticancer therapies, including radiation, anthracyclines, cisplatin, taxanes, 5-fluorouracil (5-FU), flavopiridol, bevacizumab and trastuzumab (Figure 3). Preliminary studies of tumour cells in culture suggest that vorinostat may be additive and even synergistic with radiation therapy and selected chemotherapeutic agents in inhibiting proliferation or inducing apoptosis (Table 4).

\section{SUMMARY}

Vorinostat, a potent inhibitor of Classes I and II HDAC activity with an IC50 $<86 \mathrm{nM}$, induces histone and protein acetylation and alters gene expression. Vorinostat blocks growth promoting signal transduction pathways and the proliferation of a broad spectrum of cultured cancer cells. Parenteral and oral administration of vorinostat at doses producing little or no toxicity to normal cells results in growth arrest in rodent models of several solid tumours and haematological malignancies, including prostate cancer, leukaemia, breast cancer, colon cancer and lung cancer. The mechanism underlying the antitumour action of vorinostat is not yet clear but may involve changes in the expression of specific genes via acetylation of histones and transcription factors as well as nontranscriptional effects such as inhibition of mitosis. Further research to delineate the mechanism(s) of action of vorinostat and other HDAC inhibitors may pave the way to developing rational combinations with other chemotherapeutic agents and perhaps ultimately to optimising chemotherapy regimens for cancer patients.

\section{ACKNOWLEDGEMENTS}

Writing assistance for this paper was provided by Jan S Redfern, $\mathrm{PhD}$, and funding was provided by Merck \& Co. Inc., Whitehouse Station, NJ 08889.
Chinnaiyan P, Vallabhaneni G, Armstrong E, Huang SM, Harari PM (2005) Modulation of radiation response by histone deacetylase inhibition. Int $J$ Radiat Oncol Biol Phys 62: 223-229

Cohen LA, Amin S, Marks PA, Rifkind RA, Desai D, Richon VM (1999) Chemoprevention of carcinogen-induced mammary tumorigenesis by the hybrid polar cytodifferentiation agent, suberanilohydroxamic acid (SAHA). Anticancer Res 19: 4999-5005

Cohen LA, Marks PA, Rifkind RA, Amin S, Desai D, Pittman B, Richon VM (2002) Suberoylanilide hydroxamic acid (SAHA), a histone deacetylase inhibitor, suppresses the growth of carcinogen-induced mammary tumors. Anticancer Res 22: $1497-1504$

Desai D, Das A, Cohen L, el Bayoumy K, Amin S (2003) Chemopreventive efficacy of suberoylanilide hydroxamic acid (SAHA) against 4-(methylnitrosamino)-1-(3-pyridyl)-1-butanone (NNK)-induced lung tumorigenesis in female A/J mice. Anticancer Res 23: 499-503

Duvic M, Talpur R, Zhang C, Goy A, Richon VM, Frankel SR (2005) Phase II trial of oral suberoylanilide hydroxamic acid (SAHA) for cutaneous 
T-cell lymphoma (CTCL) unresponsive to conventional therapy. J Clin Oncol 23(suppl): 577s (abstract 6571)

Eyupoglu IY, Hahnen E, Buslei R, Siebzehnrubl FA, Savaskan NE, Luders M, Trankle C, Wick W, Weller M, Fahlbusch R, Blumcke I (2005) Suberoylanilide hydroxamic acid (SAHA) has potent anti-glioma properties in vitro, ex vivo and in vivo. J Neurochem 93: 992-999

Fenrick R, Hiebert SW (1998) Role of histone deacetylases in acute leukemia. J Cell Biochem Suppl 30-31: 194-202

Finnin MS, Donigian JR, Cohen A, Richon VM, Rifkind RA, Marks PA, Breslow R, Pavletich NP (1999) Structures of a histone deacetylase homologue bound to the TSA and SAHA inhibitors. Nature 401: 188-193

Glaser KB, Staver MJ, Waring JF, Stender J, Ulrich RG, Davidsen SK (2003) Gene expression profiling of multiple histone deacetylase (HDAC) inhibitors: defining a common gene set produced by HDAC inhibition in T24 and MDA carcinoma cell lines. Mol Cancer Ther 2: 151-163

Gregory PD, Wagner K, Horz W (2001) Histone acetylation and chromatin remodeling. Exp Cell Res 265: 195-202

Grignani F, De Matteis S, Nervi C, Tomassoni L, Gelmetti V, Cioce M, Fanelli M, Ruthardt M, Ferrara FF, Zamir I, Seiser C, Grignani F, Lazar MA, Minucci S, Pelicci PG (1998) Fusion proteins of the retinoic acid receptor-alpha recruit histone deacetylase in promyelocytic leukaemia. Nature 391: 815-818

Grunstein M (1997) Histone acetylation in chromatin structure and transcription. Nature 389: $349-352$

Gui CY, Ngo L, Xu WS, Richon VM, Marks PA (2004) Histone deacetylase (HDAC) inhibitor activation of $\mathrm{p} 21 \mathrm{WAF} 1$ involves changes in promoterassociated proteins, including HDAC1. Proc Natl Acad Sci USA 101: $1241-1246$

Halkidou K, Gaughan L, Cook S, Leung HY, Neal DE, Robson CN (2004) Upregulation and nuclear recruitment of HDAC1 in hormone refractory prostate cancer. Prostate 59: $177-189$

He LZ, Guidez F, Tribioli C, Peruzzi D, Ruthardt M, Zelent A, Pandolfi PP (1998) Distinct interactions of PML-RARalpha and PLZF-RARalpha with co-repressors determine differential responses to RA in APL. Nat Genet 18: $126-135$

He LZ, Tolentino T, Grayson P, Zhong S, Warrell Jr RP, Rifkind RA, Marks PA, Richon VM, Pandolfi PP (2001) Histone deacetylase inhibitors induce remission in transgenic models of therapy-resistant acute promyelocytic leukemia. J Clin Invest 108: $1321-1330$

Johnstone RW, Licht JD (2003) Histone deacetylase inhibitors in cancer therapy: is transcription the primary target? Cancer Cell 4: 13-18

Kelly WK, O'Connor OA, Krug LM, Chiao JH, Heaney M, Curley T, Macgregore-Cortelli B, Tong W, Secrist JP, Schwartz L, Richardson S, Chu E, Olgac S, Marks PA, Scher H, Richon VM (2005) Phase I study of an oral histone deacetylase inhibitor, suberoylanilide hydroxamic Acid, in patients with advanced cancer. J Clin Oncol 23: $3923-3931$

Kelly WK, Richon VM, O'Connor O, Curley T, MacGregor-Curtelli B, Tong W, Klang M, Schwartz L, Richardson S, Rosa E, Drobnjak M, Cordon-Cordo C, Chiao JH, Rifkind R, Marks PA, Scher H (2003) Phase I clinical trial of histone deacetylase inhibitor: suberoylanilide hydroxamic acid administered intravenously. Clin Cancer Res 9: $3578-3588$

Kim MS, Blake M, Baek JH, Kohlhagen G, Pommier Y, Carrier F (2003) Inhibition of histone deacetylase increases cytotoxicity to anticancer drugs targeting DNA. Cancer Res 63: 7291-7300

Lemercier C, Brocard MP, Puvion-Dutilleul F, Kao HY, Albagli O, Khochbin S (2002) Class II histone deacetylases are directly recruited by BCL6 transcriptional repressor. J Biol Chem 277: 22045-22052
Marchion DC, Bicaku E, Daud AI, Richon V, Sullivan DM, Munster PN (2004) Sequence-specific potentiation of topoisomerase II inhibitors by the histone deacetylase inhibitor suberoylanilide hydroxamic acid. J Cell Biochem 92: 223-237

Marks P, Rifkind RA, Richon VM, Breslow R, Miller T, Kelly WK (2001) Histone deacetylases and cancer: causes and therapies. Nat Rev Cancer 1: 194-202

Marks PA, Dokmanovic M (2005) Histone deacetylase inhibitors: discovery and development as anticancer agents. Expert Opin Investig Drugs 14: $1497-1511$

Marks PA, Richon VM, Miller T, Kelly WK (2004) Histone deacetylase inhibitors. Adv Cancer Res 91: 137-168

Nimmanapalli R, Fuino L, Stobaugh C, Richon V, Bhalla K (2003) Cotreatment with the histone deacetylase inhibitor suberoylanilide hydroxamic acid (SAHA) enhances imatinib-induced apoptosis of BcrAbl-positive human acute leukemia cells. Blood 101: 3236-3239

Ocker M, Alajati A, Ganslmayer M, Zopf S, Luders M, Neureiter D, Hahn EG, Schuppan D, Herold C (2005) The histone-deacetylase inhibitor SAHA potentiates proapoptotic effects of 5-fluorouracil and irinotecan in hepatoma cells. J Cancer Res Clin Oncol 131: 385-394

Rahmani M, Reese E, Dai Y, Bauer C, Payne SG, Dent P, Spiegel S, Grant S (2005) Coadministration of histone deacetylase inhibitors and perifosine synergistically induces apoptosis in human leukemia cells through Akt and ERK1/2 inactivation and the generation of ceramide and reactive oxygen species. Cancer Res 65: 2422-2432

Rahmani M, Yu C, Dai Y, Reese E, Ahmed W, Dent P, Grant S (2003) Coadministration of the heat shock protein 90 antagonist 17-allylamino17-demethoxygeldanamycin with suberoylanilide hydroxamic acid or sodium butyrate synergistically induces apoptosis in human leukemia cells. Cancer Res 63: 8420-8427

Richon VM, Sandhoff TW, Rifkind RA, Marks PA (2000) Histone deacetylase inhibitor selectively induces p21WAF1 expression and gene-associated histone acetylation. Proc Natl Acad Sci USA 97: 10014-10019

Rundall BK, Denlinger CE, Jones DR (2004) Combined histone deacetylase and NF-kappaB inhibition sensitizes non-small cell lung cancer to cell death. Surgery 136: 416-425

Sakajiri S, Kumagai T, Kawamata N, Saitoh T, Said JW, Koeffler HP (2005) Histone deacetylase inhibitors profoundly decrease proliferation of human lymphoid cancer cell lines. Exp Hematol 33: 53-61

Sandor V, Robbins AR, Robey R, Myers T, Sausville E, Bates SE, Sackett DL (2000) FR901228 causes mitotic arrest but does not alter microtubule polymerization. Anticancer Drugs 11: $445-454$

Secrist JP, Zhou X, Richon VM (2003) HDAC inhibitors for the treatment of cancer. Curr Opin Investig Drugs 4: 1422-1427

Song J, Noh JH, Lee JH, Eun JW, Ahn YM, Kim SY, Lee SH, Park WS, Yoo NJ, Lee JY, Nam SW (2005) Increased expression of histone deacetylase 2 is found in human gastric cancer. APMIS 113: $264-268$

Ungerstedt JS, Sowa Y, Xu WS, Shao Y, Dokmanovic M, Perez G, Ngo L, Holmgren A, Jiang X, Marks PA (2005) Role of thioredoxin in the response of normal and transformed cells to histone deacetylase inhibitors. Proc Natl Acad Sci USA 102: 673-678

Verdin E, Dequiedt F, Kasler HG (2003) Class II histone deacetylases: versatile regulators. Trends Genet 19: 286-293

Warrener R, Beamish H, Burgess A, Waterhouse NJ, Giles N, Fairlie D, Gabrielli B (2003) Tumor cell-selective cytotoxicity by targeting cell cycle checkpoints. FASEB J 17: 1550-1552

Zhu P, Martin E, Mengwasser J, Schlag P, Janssen KP, Gottlicher M (2004) Induction of HDAC2 expression upon loss of APC in colorectal tumorigenesis. Cancer Cell 5: 455-463 